\title{
ALGUMAS CONSIDERAÇÕES SOBRE 0 EFEITO DO FENÔMENO EL NIÑO SOBRE FEIÇÕES COSTEIRAS AO LONGO DA COSTA BRASILEIRA
}

\author{
Guilherme Borges FernandeZ \\ Universidade Federal Fluminense \\ DieTer Muehe \\ Universidade Federal do Rio de Janeiro
}

\begin{abstract}
A influência direta do efeito El Niño na alteração morfológica e do balanço sedimentar dos ambientes geomorfológicos da costa Brasileira ainda é um tema pouco explorado. Tal fato deve-se provavelmente a ausência de seqüências de observações de longo prazo, uma vez que os monitoramentos efetuados normalmente estão acoplados a demandas relacionadas a conclusão de pesquisas, dissertações ou teses que normalmente não ultrapassam quatro anos de levantamentos. Apesar disso, a observação de anomalias nos padrões de dinâmica sedimentar em alguns pontos do litoral foram associados a ocorrência de efeito El Niño.

O objetivo deste trabalho é apresentar as características gerais do fenômeno El Niño/Oscilação Sul (ENOS) e os mecanismos de alteração climática que invariavelmente modificam o padrão de ventos e precipitação que afetam a costa brasileira modificando o padrão normal morfodinâmico de algumas áreas costeiras no Brasil. Para tanto foi feita uma extensiva pesquisa em publicações e anais de congressos nacionais no sentido de se identificar alguns indicativos da ligação entre a anomalia na interação oceano atmosférica e a geomorfologia litorânea brasileira.
\end{abstract}

\section{O efeito El Niño}

O El Niño/Oscilação Sul (ENOS) é um fenômeno de escala global relacionado a um forte acoplamento entre o sistema oceânico e a atmosfera que se manifesta ao longo da zona equatorial/tropical do Pacífico Sul (philander, 1983; CANE, 1992, 
entre outros). Neste sistema, a componente oceânica se define por $E l$ Niño (EN), que se manifesta pelo aumento anômalo das temperaturas superficiais da massa líquida na parte oriental do Pacífico entre o equador e os trópicos. A componente atmosférica é dada pela Oscilação Sul (OS), que funciona como um balanço de massa atmosférica de grande escala, envolvendo trocas de ar entre os hemisférios leste e oeste, centradas nas latitudes tropicais e subtropicais, sendo que os centros de ação se localizam na Indonésia e no Pacífico Tropical Sul (Souza, et al., 1998).

Em termos numéricos a OS é medida através do Índice de Oscilação Sul (IOS) que corresponde a diferença normalizada das pressões obtidas no nível do mar entre duas estações: uma localizada na cidade de Darwin, no norte da Austrália, e a segunda no Taiti, no Pacifico Sul (DESSER \& WALLACE,1987).

Existem duas fases relacionadas ao ENOS: a fase quente que corresponde ao El Niño que se caracteriza pela ocorrência de temperaturas mais altas na superfície do Pacífico centro leste tropical, onde se observam valores negativos do IOS; e a fase fria chamada La Niña, caracterizada por anomalias negativas da temperatura superficial do oceano Pacífico centro leste, identificada através de valores positivos do IOS.

Em condições normais do padrão de circulação atmosférica, ou seja, de não ocorrência de ENOS, os ventos alísios sopram de leste para oeste, empurrando as águas mais quentes superficiais em direção ao flanco ocidental do Pacífico, influenciando diretamente no nível oceânico, que alcança 0,5 metro de elevação em relação ao nível do mar na costa oeste sul americana. Nesta situação, as águas superficiais mais quentes (resultado da insolação direta, onde são registrados valores de até $8^{\circ} \mathrm{C}$ mais quentes que na superfície oceânica da borda ocidental do continente sul americano) são empurradas na direção oeste. Com o deslocamento superficial da massa d'água em direção ao Pacífico ocidental, há ascensão vertical de águas frias de profundidade nas proximidades da costa peruana na América do Sul, que se tornam mais frias, fenômeno conhecido por Ressurgência (upwelling). Em condições de ENOS o aumento da temperatura superficial oceânica na região equatorial pacífica diminui a intensidade dos alísios, desta forma diminui a intensidade da ressurgência na costa peruana (Figura 1). A ocorrência do fenômeno então, altera o padrão climático normal em diversas áreas do globo terrestre.

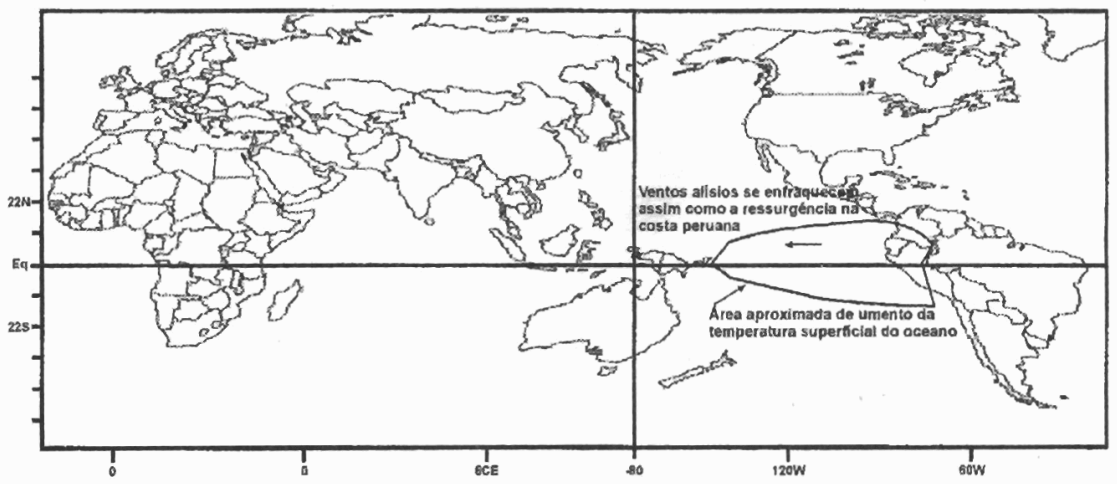


Figura 1. Mapa esquemático mostrando aproximadamente a área onde ë observado o aumento anômalo da temperatura superficial oceânica no Pacífico equatorial/tropical, associado a resultante atmosférica verificada pela diminuição da intensidade dos ventos alísios. (modificado de CPTEC, endereço eletrônico)

De fato sob influência de EN nos meses de inverno do hemisfério sul, a zona intertropical central do pacífico torna-se chuvosa e a australásia e a Índia apresentam diminuição pluviométrica. O continente sul americano apresenta aumentos significativos das temperaturas na costa central da borda pacífica e aumentos pluviométricos ao sul. Na borda Atlântica as precipitações aumentam nas latitudes médias e diminuem na zona tropical. A região do Caribe se torna mais quente e seca. Esquematicamente estes efeitos estão expostos na figura 2.

Nos meses de verão no hemisfério sul sob influência de ENOS ocorre o aumento da pluviosidade na zona equatorial entre a América do Sul e o Pacífico central. A costa sudeste asiática torna-se mais seca, enquanto na península da Coréia, no Japão e no sul da Austrália são verificadas temperaturas mais elevadas, assim como também no noroeste da América do Norte. Por outro lado há um aumento dos índices pluviométricos no sudeste dos Estados Unidos e no golfo do México. Alterações dos padrões climáticos também são verificados no sudeste do continente africano, principalmente nas áreas costeiras de Moçambique e Madagascar que se tornam sensivelmente mais quentes e secas, além de índices pluviométricos mais elevados na zona equatorial do centro leste do continente africano. Estes efeitos estão sumarizados na figura 3.

\section{Efeitos Climáticos em Condiçōes El Niño nos Meses de Inverno Autral}

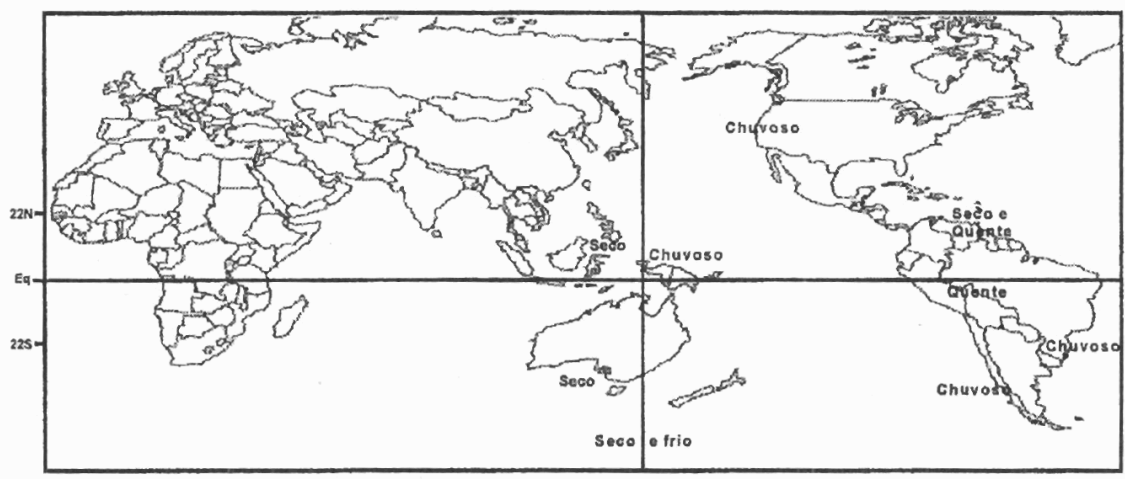

Figura 2. Efeitos climáticos observados no globo terrestre em função do efeito El Niño, durante os meses de inverno austral. (modificado de CPTEC, endereço eletrônico) 


\section{Efeitos Climáticos em Condições El Niño nos Meses de Inverno Autral}

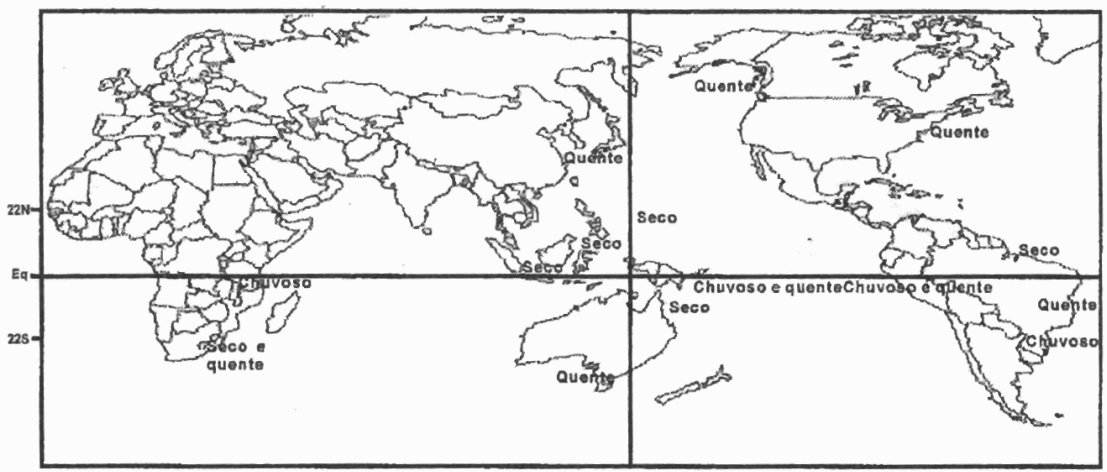

Figura 3. Efeitos climáticos observados no globo terrestre em função do efeito El Niño, durante os meses de verão austral.(modificado de CPTEC, endereço eletrônico)

Numa abordagem concentrada sobre a América do Sul pode ser observado que ao longo da borda oeste continental são registrados aumentos significativos dos índices pluviométricos desde a zona costeira do Chile até o litoral colombiano banhado pelo Pacífico. Além do aumento das chuvas ocorre a inibição do processo de ressurgência no Pacífico, afetando diretamente a economia dos países andinos, principalmente o Peru, cuja economia pesqueira depende fundamentalmente da manutenção da cadeia trófica influenciada pela ressurgência. A manutenção da cadeia é função direta da dispersão de nutrientes na superfície, que se encontram diluídos em águas mais profundas, que são ressuspendidos pela migração vertical da massa d'água junto a costa peruana. Assim em anos de ENOS, há uma sensível diminuição no volume da pesca, devido fundamentalmente a diminuição da produção primária que serve de base para a cadeia alimentar do necton.

No Brasil, em anos de ENOS foram registradas chuvas pronunciadas na Região Sul e aumentos de temperatura na Região Sudeste, além de secas pronunciadas no semi-árido nordestino (CAVIEDES, 1973; ALVES \& RIPPELI, 1992; CAVALCANTI, 1996; RELATÓRIO DA COMIISSÃO EL NIÑO, 1997; SOUZA et al, 1998). No Nordeste em particular, SERVAIN \& LEGLER (1986); NOBRE \& SUKLA (1996) e SOUZA (1997) apontam também influência do Padrão Dipolo (PD) nas alterações dos índices pluviométricos no sertão do Nordeste brasileiro. $\mathrm{O}$ PD é um outro componente que se estabelece no sistema oceano/atmosfera, e se manifesta principalmente nos meses de outono no Hemisfério Sul (SOUZA, 1997). Trata-se de anomalias simultâneas da temperatura superficial do oceano Atlântico, ao longo da zona equatorial, se manifestando por sinais opostos da temperatura superficial oceânica nos dois lados (norte e sul) do Atlântico equatorial. Sua influência foi registrada no deslocamento da Zona de Convergência Intertropical (ZCIT) 
(NOBRE E SUKLA, 1996). Da mesma forma que o ENOS, o PD, possui duas fases: a fase positiva, onde se observam valores mais elevados na zona norte equatorial do oceano Atlântico, ocasionando uma migração da ZCIT para norte, conseqüentemente na fase negativa do Dipolo, o gradiente térmico se desloca para o Hemisfério Sul. Analisando os índices pluviométricos no semi-árido nordestino, correlacionados ao PD, SOUZA et al. (1998) registrou a relação inversa entre os índices pluviométricos e a fase do dipolo, isto é, quando da fase positiva há um sensível decréscimo das chuvas, e na fase negativa aumenta o volume pluviométrico. Os mesmos autores registraram a diminuição dos índices pluviométricos em anos de ENOS em todo o semi-árido nordestino, exceção feita ao norte baiano. O padrão se inverteu a partir do registro do aumento significativo da pluviosidade nesta área (sertão) em anos de episódio La Niña.

O deslocamento da ZCIT afeta diretamente o deslocamento em latitude da célula semi-estacionária de Alta Pressão do Atlântico Sul (NIMER, 1989; DOMINGUEZ \& BITENCOURT, 1994). Esta célula é a principal responsável pela circulação atmosférica ao longo da costa brasileira (BIGARELA, 1972; NIMER, 1989; FONZAR, 1994), dominando a parte norte e leste do litoral brasileiro, sendo responsável pelos ventos alísios que atingem esta porção do continente (Fig.4). Nos meses de verão a célula semifixa gera ventos nas direções SE e E que afetam as áreas ao norte do paralelo de $10^{\circ} \mathrm{S}$, sendo que a partir desta latitude tem direção $\mathrm{NE}$ até o paralelo $40^{\circ} \mathrm{S}$, afetando deste forma todo o litoral brasileiro (NIMER, 1989; FONZAR, 1994). Deste modo os ventos atingem frontalmente a costa nordestina até as proximidades do cabo Calcanhar no Rio Grande do Norte e assume direções quase paralelas ao litoral a partir do cabo até o estuário do Amazonas (FONZAR, 1994).

O padrão de ventos gerados pela célula de Alta Pressão do Atlântico Sul é constantemente substituído por ventos do quadrante sul originário das altas latitudes, próximas ao pólo Sul. Os ventos de sul se originam das Frentes Polares Antárticas, sob a forma de anticiclones migratórios das altas para as baixas latitudes. Ao se formarem, migram em função de diferenças de pressão entre as áreas continentais e oceânicas, se dividido em duas frentes pelo efeito orográfico do planalto central brasileiro. A parte que se desloca afetando o leste da América do Sul, bordeja o litoral atingindo latitudes de até $10^{\circ}$, em suas condições mais extremas, ficando restritas aos trópicos em situações brandas (FONZAR, 1994). 


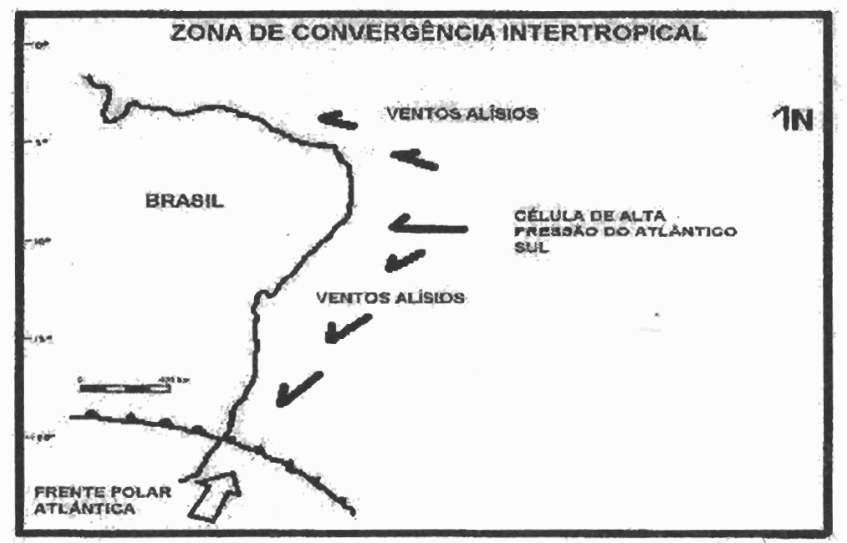

Fig. 4. Padrão geral de circulação ao longo da costa brasileira. (modificado de Dominguez e Bittencourt, 1994)

Em anos sob efeito de efeito El Niño o padrão atmosférico se modifica sensivelmente. $\mathrm{O}$ avanço das frentes polares, comuns nos meses de inverno, é inibido pelo aumento de intensidade dos ventos alísios, freando a migração do anticiclone polar. Este por outro lado permanece semi-estacionário no litoral da Região Sul gerando eventos catastróficos como documentados nos anos de 1982/ 83 , onde houve significativas perdas na safra devido a enchentes sucessivas (RELATÓRIO DA COMISSÃO EL NIÑO, 1997). A fraca penetração das frentes permite periodos prolongados de veranicos no inverno na Região Sudeste e na borda leste do litoral nordestino pelo aumento da força da célula de alta pressão, que se intensifica, inibindo precipitações nesta área (RELATÓRIO DA COMISSÃO EL NIÑO, 1997).

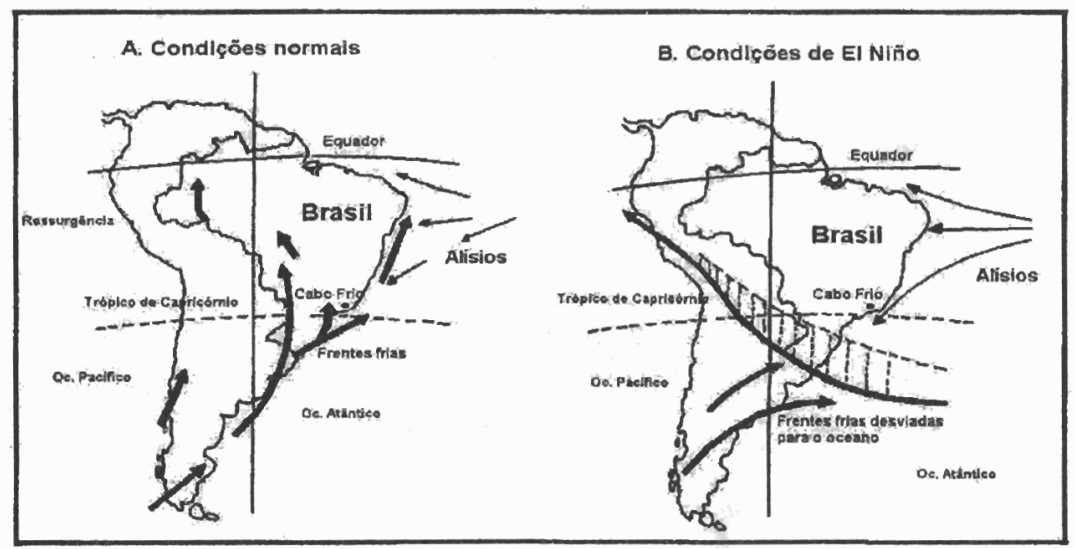

Figura 5. Esquema comparativo entre as condições normais do padrão de circulação atmosférica e condições El Niño. Modificado de TURC et.al.1999. 
Por outro lado sob condições de La Niña a célula de Alta Pressão se enfraquece. Este enfraquecimento favorece a migração de frentes frias, que atingem sistematicamente latitudes abaixo de $20^{\circ}$ aumentando os índices pluviométricos e diminuído as temperaturas na região Sudeste (RELATÓRIO DA COMISSÃO EL NIÑO, 1997). MUEHE \& FERNANDEZ (2004) e FERNANDEZ (2003) analisando o número de frentes frias que atingem o litoral fluminense, apontam que durante a ocorrência de EN há de fato uma sensível diminuição das frentes frias que atingem esta parte do litoral. É interessante ressaltar que os autores não verificaram nenhuma diminuição no número de frentes geradas nas altas latitudes e sim que estas não atingiam o litoral do Rio de Janeiro, corroborando a sugestão de bloqueio destas frentes no litoral sul do Brasil.

A partir da discussão apresentada, o que se verifica de maneira resumida é que durante a ocorrência de fenômeno EN ocorre um sensível decréscimo pluviométrico no litoral nordestino. Associado a isso o fortalecimento da atividade da ATAS intensifica os ventos alísios que geram ventos e ondas nas direções $\mathrm{E} / \mathrm{SE}$ para o litoral nordestino e E/NE para a costa da região Sudeste. Por outro lado, o bloqueio das frentes frias inibe que ondas do quadrante sul avancem para o litoral das regiões Nordeste e Sudeste do Brasil que, como já dito, ficam sob maior influência dos alísios e consequientemente de ondas geradas ppor estes ventos.

\section{Exemplos da influência do fenômeno El Niño na geomorfologia costeira ao longo do litoral brasileiro}

\section{Praias de Itapoá (litoral norte de Santa Catarina)}

As praias do Município de Itapoá (SC) se estendem por $32 \mathrm{~km}$ próximas ao limite estadual com o Paraná, compreendidas entre o estuário do rio Saí-Guaçu (extremo norte) até a baia de São Francisco do Sul. A orientação da linha de costa é praticamente norte-sul de um litoral retilíneo formado por praias arenosas (SOUZA \& ANGULO, 1999). Nesta área SOUZA \& ANGULO (1999) analisaram dados referentes a levantamentos de perfis topográficos de praia durante agosto de 1996 e junho de 1998 e fotografias aéreas em 1957, 1978 e 1995. O acompanhamento das variações topográficas foi direcionado para uma análise morfodinâmica das praias associadas a análises de fotografias aéreas com o objetivo de mostrar tendências de progradação ou retrogradação da linha de costa.

Os resultados da análise das variações topográficas dos perfis mostraram que no período de junho de 1997 a março de 1998 em sete dos nove perfis foram identificados intensos processos erosivos. Para os autores da pesquisa, a erosão ocorrida no período foi favorecida pela ocorrência de valores muito baixos do IOS, isto é, forte ocorrência de $\mathrm{El} \mathrm{Niño,} \mathrm{que} \mathrm{determinou} \mathrm{o} \mathrm{aumento} \mathrm{da} \mathrm{freqüência} \mathrm{das}$ 
ondas de tempestades na região Sul do Brasil, pela permanência semi-estacionária das frentes frias. Outro fator associado ao ENOS que pode ter contribuído para o aumento das taxas de erosão em Itapoá foi aumento da pluviosidade. Como a área é fortemente influenciada por estuários, que desembocam nos dois extremos linha de costa estudada, forma-se uma série de barras sedimentares submersas condicionadas por correntes de vazante. $\mathrm{O}$ aumento da pluviosidade aumentou sensivelmente o volume da descarga fluvial. A partir do aumento do material disponível associado ao aumento da velocidade das córrentes, houve alterações na configuração do lobo frontal do delta submerso, que alterou o padrão de refração das ondas que geraram novas convergentes de ortogonais, aumentando as taxas de erosão na praia. Tal padrão foi identificado por ANGULO (1993) na baia de Guaratuba (PR) e pôde também ser aplicado no litoral norte catarinense.

SOUZA \& ANGULO (1999) sugerem porém, a continuidade do monitoramento quando da inversão do IOS, pois com o número reduzido de observações não permitem conclusões diretas entre o fenômeno climático e a erosão nas praias catarinenses.

\section{Praia da Armação. Salvador (Bahia)}

A praia da Armação se localiza na cidade de Salvador no flanco norte da baía de Todos os Santos. A praia tem a forma de uma suave enseada ancorada entre promontórios rochosos com extensão de $3 \mathrm{~km}$, com alinhamento SO/NE. O clima é tropical úmido com alta pluviosidade, sendo os ventos característicos de NE-E-SE soprando ao longo de todo o ano. Apesar de pouco representativos ( $5 \%$ do total) os ventos sul ocorrem em alta intensidade na escala Beaufort (DHN, 1976).

Nesta praia, BITTENCOURT et al (1987) e FARIAS et al (1985) realizaram uma série de levantamentos topográficos em três perfis de praia, com objetivo de identificação do padrão morfodinâmico. Inicialmente foram realizados perfis topográficos por 19 meses consecutivos (FARIAS et al, 1985), sendo posteriormente estendido o período de observações por mais 12 meses (BITTENCOURT et al, 1987). Neste acompanhamento ficou comprovado a ligação entre a manutenção do padrão de ventos com o sentido da deriva litorânea o que acarretou a ligação entre o transporte de sedimentos e a obliqüidade de incidência das ondas.

Como a praia é ancorada entre promontórios rochosos ficou constatado pelos autores o bloqueio do trânsito de sedimentos para fora do arco. As alterações morfológicas observadas se estabeleceram a partir do engordamento de uma extremidade estando diretamente relacionada a erosão da outra, de maneira que caracteriza um movimento rotacional em praia encaixada. Estes processos erosivos e acrescionais em flancos distintos da praia não foram relacionados a alteração entre perfis de verão e inverno e sim a sazonalidade do padrão de ventos na área 
(FARIAS et $a l, 1985)$. Deste modo o perfil do flanco sul sofreu erosão quando predominaram ventos de SSE. A inversão deste processo ocorreu devido a predominância de ventos ENE. O perfil localizado no meio do arco pouco se alterou ao longo do monitoramento.

Os autores porém, revelaram que o monitoramento quando realizado durante o ano de 1983, ano de forte ocorrência de El Niño, houve alterações no padrão esperado. De fato, no ano em que foram efetuados os levantamentos, os autores constataram a sensível diminuição dos ventos de sul e das ondas com maior poder de transporte associadas a estes ventos. Como conseqüência o transporte de sul para norte foi inibido, ocorrendo apenas quando ventos de SSE sopraram. Uma vez que estes também foram pouco participativos em termos percentuais, acarretou um lento transporte de sedimentos para o norte do arco. A diminuição dos ventos de tempestade responsáveis pelo balanço sedimentar de sul para norte, impulsionados pela entrada das frentes foi interpretada pelos autores como resultado direto do efeito El Niño, que influenciou também de forma direta o padrão de sedimentação na praia.

\section{Dunas móveis do litoral nordestino}

As dunas móveis são observadas em campos extensos ao longo de grande parte da zona costeira do Nordeste do Brasil (MUEHE, 1998). DOMINGUEZ \& BITTENCOURT (1994) associam a presença destes campos devido ao clima, pois as dunas móveis neste setor do litoral se posicionam nas áreas onde são observados pelo menos quatro meses secos durante o ano. Estas áreas estão posicionadas desde a costa do Rio Grande do Norte até o Maranhão, estando também presente junto a desembocadura do rio São Francisco.

O mecanismo de suprimento das dunas é dado pela remoção de material seco da berma da praia para o interior pelos ventos alísios, que sopram no sentido mar-terra. O processo de migração é climaticamente controlado, pois nos meses de inverno-primavera, que são os meses chuvosos, ocorrem as menores taxas uma vez que os sedimentos estão mais umidecidos dificultando seu transporte (BITENCOURT, DOMINGUEZ \& MOITA FILHO, 1990).

RODRIGUES (1999) ao estudar as taxas de transporte eólico na região de Cauípe (oeste cearense) observou uma sensível diferença entre os anos de 1996 e 1997. Durante o ano de 1996 (IOS positivo) os valores obtidos foram da ordem de $107 \mathrm{~m}^{3} / \mathrm{m} /$ ano. No ano de 1997 , ano de forte efeito El Niño a taxa apresentou um ligeiro aumento, passando para $120 \mathrm{~m}^{3} / \mathrm{m} / \mathrm{ano}$. Este resultado foi explicado pelo autor pelo fato de que em anos de El Niño há diminuição dos índices pluviométricos e aumentos da atividade dos ventos alísios, mobilizando deste modo maiores taxas de sedimentos. 
Deste modo em anos de El Niño devido a diminuição de índices pluviométricos e conseqüentemente os sedimentos permanecendo mais secos durante uma maior período de tempo, ocorrem as maiores taxas de migração.

Em outra localidade do litoral nordestino, na região de Paracuru (CE)CASTRO (2001) obteve resultados similares, com maior atividade de transporte de sedimentos em anos El Niño e diminuição em anos La Niña.

\section{Dunas frontais da Massambaba Leste}

As dunas frontais na Massambaba Leste se localizam no extremo oriental do cordão litorâneo que liga a praia Grande em Arraial do Cabo até Saquarema. A área de localização das dunas frontais é desfavorecida no sentido de sua ocorrência e manutenção de seu estoque sedimentar, uma vez que a área é submetida a retaguarda por ventos de nordeste que atuam na retirada de sedimentos das dunas em direção a praia. Por outro lado o equilíbrio no balanço de sedimentos nas dunas ocorre principalmente pela manutenção das características ambientais naturais, isto é ainda mantida sem interferência de construções.

De fato o conjunto de dunas pode ser condicionado em tempo geológico pelo recuo relativo do nível do mar nos últimos cinco mil de anos (MARTIN \& SUGUIO, 1987) e atualmente pela transposição de ondas de tempestade, recuperando o estoque sedimentar das dunas (FERNANDEZ \& MUEHE, submetido; FERNANDEZ E MUEHE, 2004; FERNANDEZ, 2003). O equilíbrio sedimentar deste sistema de dunas porém é perturbado quando os dados volumétricos do balanço sedimentar é correlacionado com anos sob influência de efeito El Niño.

FERNANDEZ \& MUEHE (2004) demonstraram que as variações volumétricas medidas num segmento do campo de dunas da Massambaba entre 1995 e 2003 é influenciada durante os anos sob influência de ENOS. Os dados dos autores reportam uma sensível queda do estoque sedimentar das dunas durante os anos EI Niño, isto é entre 1997 e 2001 . Tal fato foi associado ao bloqueio das frentes frias abaixo da linha tropical, o que favoreceu a maior incidência de ventos de NE, que atingem as dunas no sentido terra-mar. Desta forma os constantes ventos em tal direção erodiram as dunas diminuindo sensivelmente o volume de sedimentos do segmento estudado. Com o bloqueio das frentes frias ficou constatada a diminuição da ocorrência de frentes frias na costa fluminense, mais especificamente na altura de Cabo Frio, de maneira que foram diminuídos os eventos de transposição das ondas na área da Massambaba, o que inibiu a recuperação do estoque sedimentar.

É interessante notar que pelos dados publicados pelos referidos autores durante anos normais mesmo com tendência para El Niño com para La Niña o balanço sedimentar apresentou pequena recuperação dos estoques de material. Em comparação com anos La Niña apesar das quedas no balanço volumétricos esțes foram sensivelmente menores que em anos ENOS. 


\section{Conclusão}

Os dados aqui expostos mostram que, apesar das dificuldades de se relacionar eventos de acoplagem oceano-atmosfera que regem o ritmo climático na Terra, pode ser um importante elemento a ser levado em consideração para se explicar o comportamento morfodinâmico de feições costeiras na costa brasileira. Desta forma, as perspectivas de análise na zona costeira prioritariamente voltada para eventos catastróficos podem ser ampliadas para correlações mais amplas para o entendimento do balanço sedimentar, principalmente em fenômenos que vêm sendo investigados de forma sistemática com é o caso do ENOS.

\begin{tabular}{|c|c|c|c|}
\hline \multicolumn{3}{|c|}{ Tabela 1: Resultados do balanço sedimentar em anos El Niño and La Niña. } \\
\hline Ano & Evento & $\begin{array}{c}\text { Balanço sedimentar: } \\
\text { El Niño }\left(\mathrm{m}^{3}\right)\end{array}$ & Balanço sedimenta: La Niña $\left(\mathrm{m}^{3}\right)$ \\
\hline 1996 & La Niña/Normal & & 273,8 \\
\hline 1997 & El Niño & $-913,7$ & $-544,11$ \\
\hline 1998 & La Niña & & $-329,4$ \\
\hline 1999 & La Niña & & 175,85 \\
\hline 2000 & La Niña & & \\
\hline 2001 & El Niño & $-1190,5$ & $-985,3$ \\
\hline 2002 & El Niño/Normal & 364,2 & \\
\hline Results & & $-1726,3$ & \\
\hline
\end{tabular}

Resumo: Este trabalho tem como objetivo principal traçar algumas considerações sobre a influência do efeito El Niño no balanço de sedimentos em algumas regiões da costa brasileira. O efeito El Niño atua ao longo do litoral bloqueando a subida para as baixas latitudes. Deste modo uma vez que há influência direta deste processo no padrão ritmo do clima de ondas e nos ventos, forçantes fundamentais na dinâmica sedimentar da zona costeira foi constatado discrepâncias do padrão normal desta dinâmica em alguns pontos da costa brasileira. Os resultados mostraram que na costa nordestina em anos El niño há intensificação do transporte eólicos no Ceará. Na Bahia a dinâmica de algumas praiaz encaixadas foi afetada na sua morfodinâmica. No litoral fluminense a dinâmica de sedimentos de um campo de dunas foi severamente afetada em anos El niño. No sul do país foram observados efeitos erosivos significativos. Deste modo abre-se um nova perspectiva para estudos costeiros onde é possível se levar em conta grandes modificações do quadro morfodinâmico de algumas áreas costeiras no Brasil.

Palavras-chave: El Niño, Litoral brasileiro, Geomorfologia.

Abstract: The term El Niño and La Niña was primary used in South America Pacific coast by fishermen that observed the sharp decrease of fishery yield associated to a sporadic event of warm ocean current at the end of year (December) and lasting for several mouths. Actually the El Niño describes the warm phase of cyclical changes in the sea surface 
temperature that occur in the tropical Pacific Ocean. Actually the El Niño oscillation of the Pacific Ocean is correlated with the Southern Oscillation Index (SOI) based on the measure of the monthly differences in atmospheric pressure between the island of Tahiti and Darwin, in north Australia. The determination is done by taking the difference between each of monthly mean sea level pressure (mslp) anomalies at both locations and normalizing each of the differences by dividing them by the standard deviation of monthly differences in mslp anomalies at both locations. The value is then multiplied by 10 to create monthly SOI values. Periods of strong, protracted negative values relate to El Niño episodes, while periods of strong, protracted positive values relate to La Niña episodes. Kousky et. al. observed that during an El Niño event (1984) the blockage of the migration of cold front systems along the South Brazilian coast by a subtropical jet stream. This situation induces modifications in the wind patterns, and consequently in the wind regime and wave surges along the coast. The influence of El Niño along the Brazilian coast is poorly documented as only a few works describe the effect of this event over coastal process. Souza and Angulo (1999) found that beach profiles measured in Santa Catarina coast, between June 1997 and March 1998, present an erosional trend. This trend was related to El Niño event, because of anomalous rainfall and storm surges that affected the area during the monitoring period. In Salvador, Bahia, Bittencourt et. al. (1987) identified, during a $19^{\text {th }}$ months survey of beach profiles, different sequences of erosion and accretion in the extremities of Armação beach arc. Identified differences were associated to the influence of El Niño occurred in 1982 and 1983 that changes the wind and wave regime and created a new pattern in sediment transport along the beach arc. Dune fields, controlled by trade winds in the east and southeast directions, characterize the Northeast. The cyclical changes in sediment transport direction from the beach to the dune field are controlled by climate (Bittencourt, Dominguez and Moita Filho, 1990). Rodrigues (1999) identified an increase in the aeolian sediment supply to the dunes in Cauípe, Ceará, in 1997, due to a decrease in rainfall during this strong El Niño year. Castro (2001), studying the dune field of Paracuru, also in Ceará, has found evidences of an increase of barchan dunes during the dry season and parabolic dunes during the rainy season, related respectively to the El Niño and La Niña events. The results showed an erosive trend increased during the El Niño events with a volume reduction of $27 \%$ between the first and last survey. Besides this general trend of erosion, monthly variation in sediment volume has indicated a good relation with the Southern Oscillation Index.

Keywords: El Niño, Brazilian coastline, Geomorphology.

\section{BIBLIOGRAFIA}

ALVES, J.M.B. e REPELLI, C.A. 1992. A variabilidade pluviométrica no setor norte do Nordeste e os eventos El Niño/Oscilação Sul. RBMet., 7(2): 583-592.

BIGARELLA, J.J. 1972. Eolian environments: their caracteristics, reconition and importance. In RIGBY, J.K. \& HAMBLIN,W.K. (eds) Recognition of Ancient Sedimentary Environments. Oklahoma, Soc. Econ. Paleont. Mineral. P. 12-62. Special publication. 
BITTENCOURT, A.C.S.P.; DOMINGUEZ, J.M.\& MOITA FILHO, O. 1990. Variações texturais induzidas pelo vento nos sedimentos da face de praia (praia da Atalaia-Piauí). Revista Brasileira de Geociências, 20:201-207. BITTENCOURT, A.C.S.P.; FARIAS, F.F. \& ZANINI, A. 1987. Reflexos das variações morfodinâmicas praiais nas características texturais dos sedimentos da praia da Armação, Salvador Bahia. Revista Brasileira de Geociências, 17:276-282.

CANE, M.A. 1992. Tropical Pacific ENSO as a mode of couped system. In: Trenberth, K.E. ed. Climate System Modelling. Cambridge University Press, Cambridge. 583-614.

CASTRO, J.W.A. 2001. Geomorfologia do sistema sedimentar eólico de Paracuru - Ceará. Tese de Doutorado. Programa de Pós Graduação em Geografia da Universidade federal do Rio de Janeiro. 200p.

CAVALCANTI, I. 1996. Episódios ENOS durante a década de 1986-1996 e suas influências sobre o Brasil. Boletim Climanálise comemorativo de 10 anos. Disponível no endereço eletrônico: http://www.cptec.inpe.br/products/ climanalise/cliesp10a/nino.html

CAVIEDES, C.N. 1973. Secas and EI Niño: two simultaneous climatical hazards in South America. Proc. Assoc. Amer. Geographical, 5:44-49.

CPTEC, 1998. http.www.cptec.com

DESSER, C. \& WALLACE, J.M. El Niño events and their relation to the soutern Oscilation. Journal of Geophysics Research C92, 14189-96.

DIRETORIA DE HIDROGRAFIA E NAVEGAÇÃO - DHN . 1976. Roteiro da costa leste e do Brasil. Marinha do Brasil. 284p.

DOMINGUEZ, J.M.L. \& BITTENCOURT, A.C.S.P. 1994. Utilização de padrões de sedimentação costeira como indicadores paleoclimáticos naturais (proxies). Revista Brasileira de Geociências, 24(1):3-12.

FARIAS, F.F.; BITTENCOURT, A.C.S.P.;ZANINI, A.Jr. \& DOMINGUEZ,J.M.L. 1994. Variações temporais e espaciais na dinâmica de sedimentação da Praia da Armação- Salvador, Bahia. Revista Brasileira de Geociências, 15: 48-54.

FONZAR, B.C. 1994. A circulação atmosférica na América do Sul: os grandes sistemas planetários e subsistemas regionais que atingem o continente. Localização e trajetória. Cadernos de Geociências, Rio de Janeiro, 11:11-33.

MARTIN, L. \& SUGUIO, K. 1989. Excursion route along brazilian coast between Santos (state of São Paulo and Campos (State of Rio de Janeiro) International Symposium on Global Changes In South America during the Quaternary. São Paulo. 136 p.

1992. Variation of coastal dynamics during the last 7000 years recorded in beach-ridge plains associated with river mouths: example from the central Brazilian coast. Paleogeogr. Paleoclimatol. 99: 119-140.

MUEHE, D. \& FERNANDEZ, G.B. 1999. Efeitos de tempestade como retroalimentador do estoque de sedimentos de dunas frontais submetidas a ventos da terra para o mar. VII Congresso da Associação Brasileira de Estudos do Quaternário. Anais em CD ROM. 
MOURA, A.D. \& SUKLA,J. 1981. On the Dynamics of droughts in northeast Brazil: observations, theory and numerical experiments with a general circulation model. Jounal fo Atmospherical Science, 38(7): 2653-2675.

NIMER, E. 1989. Climatologia do Brasil. IBGE. Departamento de Recursos Naturais e Estudos Ambientais. Rio de Janeiro. 2a. Edição. 421 pags.

NOBRE,,P. \& SUKLA, J. 1996. Variations of sea surface temperature, wind stress and rainfall over the Tropical Atlantic and South America. J. Climate, 10(4) 2464-2479

NOAA, 2000. http.www. noaa.gov.

PHILANDER, S.G.H. 1983. El Niño southern oscillation phenomena. Nature, 302: 295-301.

RELATÓRIO DA COMISSÃO "El Niño". 1997. Relatório Final. Publicação especial do Governo Federal Brasileiro. Senado Federal. Brasília.

RODRIGUES, A.C.B. 1999. Taxa de migração e transporte eólico nas dunas do Ceará da Região do Cauípe - costa oeste do Estado do Ceará. VIII Congresso da Associação Brasileira de Estudos do Quaternário. Porto Seguro. Anais em CD ROM.

SERVAIN, J. \& LEGLER, D.M. 1986. Empirical otrthogonal function analyses of Tropical Atlantic temperature and wind stress:1964-1979. Journal of Geophysics Research 91 (C12): 14.181-191.

SILVA, V.P.R.; MACIEL, G.F.; ROLANDO, P.; JOSEANE,M. e GUEDES, F. Análise do nível de significância da relação entre El Niño e chuva no Nordeste do Brasil. Congresso Brasileiro de Meteorologia. Anais em CD ROM.

SOUZA, E.B.; ALVES, J.M.B.; REPELLI, C.A.; FERREIRA, N.S.; SILVA, M.E.S. e FERREIRA, A.G. 1998. Desvios percentuais da precipitação na estação chuvosa do semi-árido nordestino durante os anos de El Niño e La Niña no Pacífico Tropical e fases do Padrão Dipolo no Atlântico Tropical. Congresso Brasileiro de Meteorologia. Anais em CD ROM.

SOUZA, E.B. 1997. Um estudo observacional sobre o Padrão Dipolo de anomalias de Temperatura superficial do Mar no oceano Atlântico Tropical. Dissertação de mestrado em Meteorologia. Instituto de Pesquisas Espaciais (INPE). $138 \mathrm{pp}$.

SOUZA, M.C. e ANGULO, R. 1999. Variações da linha de costa ao longo das praias de Itapoã e os eventos de El Niño e La Niña. VII Congresso da Associação Brasileira de estudos do Quaternário (ABEQUA). Porto Seguro, Bahia. Anais em CD ROM.

XAVIER, T.M.B. e XAVIER, A.F.S. Análise do papel das temperaturas oceânicas no Atlântico e Pacífico e outras variáveis nas chuvas do Ceará. Congresso Brasileiro de Meteorologia. Anais em CD ROM. 